\title{
General anesthesia using remifentanil for Cesarean delivery in a parturient with Marfan's syndrome
}

\author{
[Anesthésie générale avec du rémifentanil pour un accouchement par césarienne \\ chez une parturiente souffrant du syndrome de Marfan]
}

Sudha Indu Singh FRCPC, Chris Brooks FrCPC, Wjotech Dobkowski FrCPC

Purpose: Due to cardiovascular and skeletal abnormalities, anesthetic management of parturients with Marfan's syndrome can be particularly challenging. Parturients with aortic root dilatation are at risk for aortic dissection. We describe the anesthetic management of a parturient with Marfan's syndrome and aortic root dilatation, who required general anesthesia for Cesarean delivery.

Clinical features: At 26 weeks gestation, a nulliparous woman with Marfan's syndrome presented to the Anesthesia Clinic. Her history revealed asymptomatic aortic root dilatation of $4 \mathrm{Imm}$, and partial correction of scoliosis with Harrington rods. Her cardiologist advised metoprolol, serial echocardiograms, and Cesarean delivery to decrease the risk of aortic dissection. At a multidisciplinary conference, a decision was made to proceed with Cesarean delivery, at term, at the cardiac surgery centre. After placement of arterial and central lines, general anesthesia was induced with remifentanil, propofol, and succinylcholine. Anesthesia was maintained with $\mathrm{N}_{2} \mathrm{O}$, sevoflurane, and remifentanil $\left(0.02-0.08 \mu \mathrm{g} \cdot \mathrm{kg}^{-1} \cdot \mathrm{min}^{-1}\right)$. Transesophageal echocardiography examination confirmed stable aortic root dilatation. The patient remained hemodynamically stable. The baby's Apgars were 4 and 8 , at one and five minutes, respectively. At the end of the procedure, the patient's trachea was extubated when she was awake. Initial postoperative care was in the intensive care unit. Both mother and baby recovered uneventfully.

Conclusions: Peripartum hemodynamic changes can be lifethreatening to the parturient with Marfan's syndrome and aortic dilatation. Anesthetic goals for delivery included preparation for possible aortic dissection, and avoidance of increased aortic root shear stress, through careful hemodynamic monitoring, and general anesthesia using remifentanil.

CAN J ANESTH 2008/55: 8/pp 526-531
Objectif : En raison d'anomalies cardiovasculaires et squelettiques, la prise en charge de l'anesthésie chez les parturientes souffrant du syndrome de Marfan peut être particulièrement exigeante. Les parturientes avec une dilatation de la racine aortique présentent un risque de dissection aortique. Nous décrivons la prise en charge de l'anesthésie pour une parturiente souffrant du syndrome de Marfan et présentant une dilatation de la racine aortique qui a nécessité une anesthésie générale pour un accouchement par césarienne.

Éléments cliniques: $\grave{A} 26$ semaines de gestation, une nullipare souffrant du syndrome de Marfan s'est présentée à la clinique d'anesthésie. Ses antécédents ont révélé une dilatation asymptomatique de la racine aortique de $41 \mathrm{~mm}$, et une correction partielle de scoliose avec des tiges de Harrington. Son cardiologue a recommandé l'administration de métoprolol, des électrocardiogrammes en série, et un accouchement par césarienne afin de réduire le risque de dissection aortique. Lors d'une conférence pluridisciplinaire, il a été décidé de réaliser l'accouchement par césarienne, à terme, dans le centre de chirurgie cardiaque. Une fois les cathéters artériel et central positionnés, l'anesthésie générale $a$ été induite avec du rémifentanil, du propofol et de la succinylcholine. L'anesthésie a été maintenue avec du $\mathrm{N}_{2} \mathrm{O}$, du sévoflurane, et du rémifentanil $\left(0,02-0,08 \mu \mathrm{g} \cdot \mathrm{kg}^{-1} \cdot \mathrm{min}^{-1}\right)$. L'examen échocardiographique transoesophagien a confirmé la dilatation de la racine aortique. L'hémodynamie de la patiente est demeurée stable. Les tests d'Apgar réalisés sur le nouveau-né ont donné des scores de 4 et 8 à une et cinq minutes, respectivement. À la fin de l'intervention, la trachée de la patiente a été extubée une fois qu'elle était réveillée. Les premiers soins postopératoires ont été donnés dans l'unité de soins intensifs. La mère et l'enfant ont tous deux récupéré sans complications.

Conclusion : Les changements hémodynamiques pendant le péripartum peuvent être fatals pour les parturientes souffrant du syndrome de Marfan avec dilatation aortique. La préparation pour

From the Department of Anesthesia \& Perioperative Medicine, Schulich School of Medicine, University of Western Ontario, London, Ontario, Canada.

Address correspondence to: Dr. Sudha Singh, Department of Anesthesia, St. Joseph's Hospital, 268 Grosvenor St., London, Ontario N6A

5V5, Canada. Phone: 519- 646-6000, ext. 64219: Fax: 519 646-6116; E-mail: isingh@uwo.ca

Financial support: None.

Accepted for publication January 15, 2008.

Revision accepted May 9, 2008. 
une dissection aortique potentielle et la prévention d'une force de cisaillement accrue sur la racine de l'aorte comptaient parmi les considérations anesthésiques pour l'accouchement. Ces objectifs ont été atteints grâce à un monitorage hémodynamique méticuleux et une anesthésie générale avec du rémifentanil.

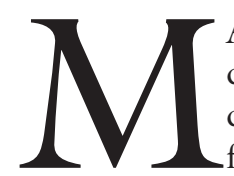

ARFAN'S syndrome is an autosomal dominantly inherited connective tissue disorder, caused by mutations of the fibrillin 1 gene found on chromosome 15. ${ }^{1}$ The disease incidence is one in 9,800 births. ${ }^{1}$ Affected individuals may present with a triad of features which include: 1) skeletal abnormalities (long, thin extremities, arachnodactyly, scoliosis); 2) ocular manifestations (lens dislocation, retinal detachment); and 3 ) cardiovascular pathology (weakness of the aortic media, aortic root dilatation, aortic valve incompetence, and mitral valvulopathy). ${ }^{2}$ Progressive aortic dilation leads to aortic dissection and is the principal cause of mortality. Pregnancy, with its unique hemodynamic (increased cardiac output and blood volume) and hormonal changes (increased estrogen weakens abnormal aortic media), represents a period of significant risk for aortic dissection in women with Marfan's syndrome. ${ }^{3,4}$

During delivery, the goals of the anesthetic management of these women are to minimize any increase in aortic root shear forces, and to monitor and prepare for possible aortic dissection. Previous authors have reported Cesarean deliveries in women with Marfan's syndrome under general ${ }^{5-7}$ and neuraxial anesthesia. ${ }^{8,9}$ We present a case of a Cesarean delivery, under general anesthesia using remifentanil, in a parturient with Marfan's syndrome and aortic root dilatation. The patient gave written, informed consent for the publication of this information, in accordance with our local institutional guidelines.

\section{Case summary}

A 33 yr-old nulliparous woman with Marfan's syndrome and aortic root dilatation, presented for anesthesia consultation at 26 weeks gestation. A transthoracic echocardiogram, completed prior to pregnancy, showed an aortic root diameter of $41 \mathrm{~mm}$. She had received counselling regarding the risks of pregnancy, and elected to continue with the pregnancy.

Her medical history was significant for scoliosis, which had been partially corrected with Harrington rods that extended from her mid-thoracic to her lower lumbar spine. She had undergone a total hip arthroplasty secondary to joint instability. Her previous general anesthetics were well tolerated. Medications included metoprolol $100 \mathrm{mg}$ po bid. Her family history was positive - both her mother and sister had Marfan's syndrome. Physical examination revealed typical Marfan's features. She weighed $70 \mathrm{~kg}$ and was $178 \mathrm{~cm}$ tall with elongated limbs and obvious scoliosis, despite corrective surgery. She had a surgical scar extending from T3 to L4. No easily identifiable landmarks were palpable, apart from her iliac crests. The remainder of her examination was unremarkable. Bloodwork, pulmonary function tests, and electrocardiogram (ECG) were normal.

Her cardiologist advised close follow-up, including serial echocardiograms during pregnancy. Metoprolol was prescribed to decrease progression of aortic dilatation, and Cesarean delivery was planned in order to minimize the risk of aortic dissection. The patient had been counselled regarding symptoms of aortic dissection and the need for emergent medical help, should she become symptomatic. We requested a multidisciplinary conference to include the anesthesiologist, obstetrician, cardiologist, cardiac surgeon, intensive care specialist, and neonatologist. By consensus, a decision was made to proceed with Cesarean delivery under general anesthesia at the cardiac surgery centre, with preparation for potential aortic replacement at 37 weeks gestation. Arrangements were made for obstetrical nursing and neonatal care to be present for the delivery and postoperative management.

The patient remained stable and was admitted to the intensive care unit (ICU) for monitoring one day prior to delivery. An echocardiogram, performed earlier that week, confirmed her aortic root diameter to be unchanged at $41 \mathrm{~mm}$. On the morning of delivery, the patient received her usual dose of metoprolol, plus metoclopramide $10 \mathrm{mg} i v$, ranitidine $50 \mathrm{mg} i v$, and sodium citrate $30 \mathrm{~mL}$ po for aspiration prophylaxis, 30 min prior to surgery.

The patient was transferred to the cardiac operating room where the obstetrician, neonatologist, cardiac surgeon, and perfusionist were present. The anesthesia team included a cardiac anesthesiologist, an obstetric anesthesiologist, and a senior anesthesia resident. Medications to control increases in heart rate (HR) and blood pressure (BP) were prepared .. The patient was positioned supine, with left lateral uterine displacement, to minimize aortocaval compression. In addition to routine monitors (non-invasive blood pressure cuff, 5 lead ECG, pulse oximeter, and axillary temperature probe), the bispectral index (BIS) monitor, as well as a left radial arterial line and a right internal jugular central line, were sited and secured. Initial vital signs 
were $\mathrm{BP}=120 / 70 \mathrm{mmHg}$ and $\mathrm{HR}=65$ beats $\cdot \mathrm{min}^{-1}$. During placement of invasive monitors, the patient was lightly sedated with a remifentanil infusion $(0.02$ $\left.0.08 \mu \mathrm{g} \cdot \mathrm{kg}^{-1} \cdot \mathrm{min}^{-1}\right)$ to minimize increases in $\mathrm{BP}$ and HR. After the abdomen and chest were prepped and draped, a modified rapid sequence induction was performed using remifentanil $1.5 \mu \mathrm{g} \cdot \mathrm{kg}^{-1} i v$, propofol 2 $\mathrm{mg} \cdot \mathrm{kg}^{-1} i v$, and succinylcholine $1.5 \mathrm{mg} \cdot \mathrm{kg}^{-1} i v$. Using a $7.0-\mathrm{mm}$ cuffed endotracheal tube, her trachea was easily intubated, without any changes in BP or HR. After confirming correct endotracheal tube placement by capnography and auscultation, the obstetrician proceeded with Cesarean delivery. A transesophageal echogram probe was inserted to monitor the patient's aortic root diameter. Anesthesia was maintained using remifentanil $\left(0.04-0.08 \mu \mathrm{g} \cdot \mathrm{kg}^{-1} \cdot \mathrm{min}^{-1}\right)$, sevoflurane $1.5 \%$ end-tidal concentration (in a mixture of $50 \%$ $\mathrm{N}_{2} \mathrm{O}$ ), and oxygen. Rocuronium $30 \mathrm{mg} i v$ was given after confirming spontaneous recovery from succinylcholine.

The patient remained hemodynamically stable, achieving a maximum systolic $\mathrm{BP}$ of $125 \mathrm{mmHg}$ and a maximum HR of 65 beats. $\mathrm{min}^{-1}$. The BIS monitor values $(40-57)$ confirmed that an adequate depth of anesthesia was maintained. Intraoperative transesophageal echocardiography examination revealed a dilated aortic root of $43 \mathrm{~mm}$, which remained unchanged. A live infant was delivered $15 \mathrm{~min}$ after induction. Initial APGAR scores were 4 and 8 , at one and five minutes, respectively. Bag-mask assisted ventilation of the newborn was required for one minute following delivery. Naloxone was not required. After delivery, oxytocin infusion $\left(20 \mathrm{U} \cdot \mathrm{L}^{-1}\right)$, antiemetics (dexamethasone $8 \mathrm{mg} i \mathrm{v}$, ondansetron $4 \mathrm{mg} i \mathrm{v}$ ), and antibiotics (gentamicin $100 \mathrm{mg} i v$, cefazolin $1 \mathrm{~g} i v$ ) were given to the mother. A cumulative dose of morphine $6 \mathrm{mg}$ iv was titrated prior to emergence. Residual paralysis was reversed with neostigmine $2.5 \mathrm{mg}$ iv and glycopyrrolate $0.4 \mathrm{mg} i \mathrm{v}$. The estimated total blood loss was $800 \mathrm{~mL}$, and the patient had received $2500 \mathrm{~mL}$ crystalloid.

After tracheal extubation, the patient complained of abdominal discomfort and nausea. Additional morphine $(6 \mathrm{mg} i \mathrm{v})$, as well as metoclopramide ( $10 \mathrm{mg} i \mathrm{v})$ and dimenhydrinate $(25 \mathrm{mg} i \mathrm{v})$, were administered, and the patient was transferred to the ICU. Upon arrival there, her BP and HR were $140 / 80 \mathrm{mmHg}$ and 57 beats. $\mathrm{min}^{-1}$, respectively. Labetolol $12.5 \mathrm{mg}$ was titrated over 15 min to maintain systolic BP < $140 \mathrm{mmHg}$. Postoperative analgesia was provided using patient-controlled hydromorphone (bolus 0.2 $\mathrm{mg}$, lockout six minutes, one-hour limit $2 \mathrm{mg}$, and no background infusion). Acetaminophen $975 \mathrm{mg}$ po and ibuprofen $400 \mathrm{mg}$ po, both qid, were ordered. The patient remained in the ICU for $24 \mathrm{hr}$, and was transferred to a step-down unit for the remainder of her hospital stay. Repeat echocardiograms were unchanged. Seven days post-partum, the patient was discharged to home with her baby. One year later, both mother and baby were continuing to do well.

\section{Discussion}

Anesthetic management of parturients with Marfan's syndrome and aortic dilation can be challenging. During pregnancy, the risk of aortic dissection is increased due to the hypervolemic, hyperdynamic circulation and the inhibition of collagen and elastin deposition in the aorta wall, attributable to estrogen. ${ }^{1}$ Some studies suggest that women with an aortic root diameter $>40$ $\mathrm{mm}$ are at increased risk of aortic dissection. ${ }^{4}$ Surgical correction is advised when aortic root dilation reaches $50 \mathrm{~mm} .{ }^{2}$ Our patient had an aortic root dilation of 41 $\mathrm{mm}$. Her medical management included reduction of arterial pressure with beta-blockers. Frequent echocardiographic imaging was performed during pregnancy to check for progressive aortic dilatation.

To avoid the increases in cardiac output associated with vaginal delivery, Cesarean delivery is recommended if there is evidence of aortic root dilation $\geq 40$ $\mathrm{mm}$ or dissection. ${ }^{10}$ The goals of anesthetic management are to decrease aortic root shear forces and to prepare for possible dissection.

The advantages and disadvantages of both regional and general anesthesia for Cesarean delivery were discussed in detail with our patient. Regional anesthesia may be associated with certain disadvantages in a parturient with Marfan's syndrome. It may be technically difficult if the patient has scoliosis or has had corrective surgery for scoliosis. Recently, there have been reports of failed spinal anesthesia in Marfan's patients, presumed to be secondary to dural ectasia, which can result in considerable dilution of anesthetic medication. ${ }^{6}$ Another important consideration is that, in the event of aortic dissection, the resulting sympathectomy from the neuraxial block may make resuscitation difficult.

A distinct advantage of general anesthesia is that, if acute dissection should occur, the airway is protected, and immediate cardiac surgery is possible. Another consideration is that inhalation agents have the potential to decrease the force of cardiac ejection and decrease the risk of aortic dissection. However, this may be associated with increased risk of uterine atony in the pregnant patient. Disadvantages of general anesthesia include the risk of hypertensive response to intubation, which could have been life-threatening in 


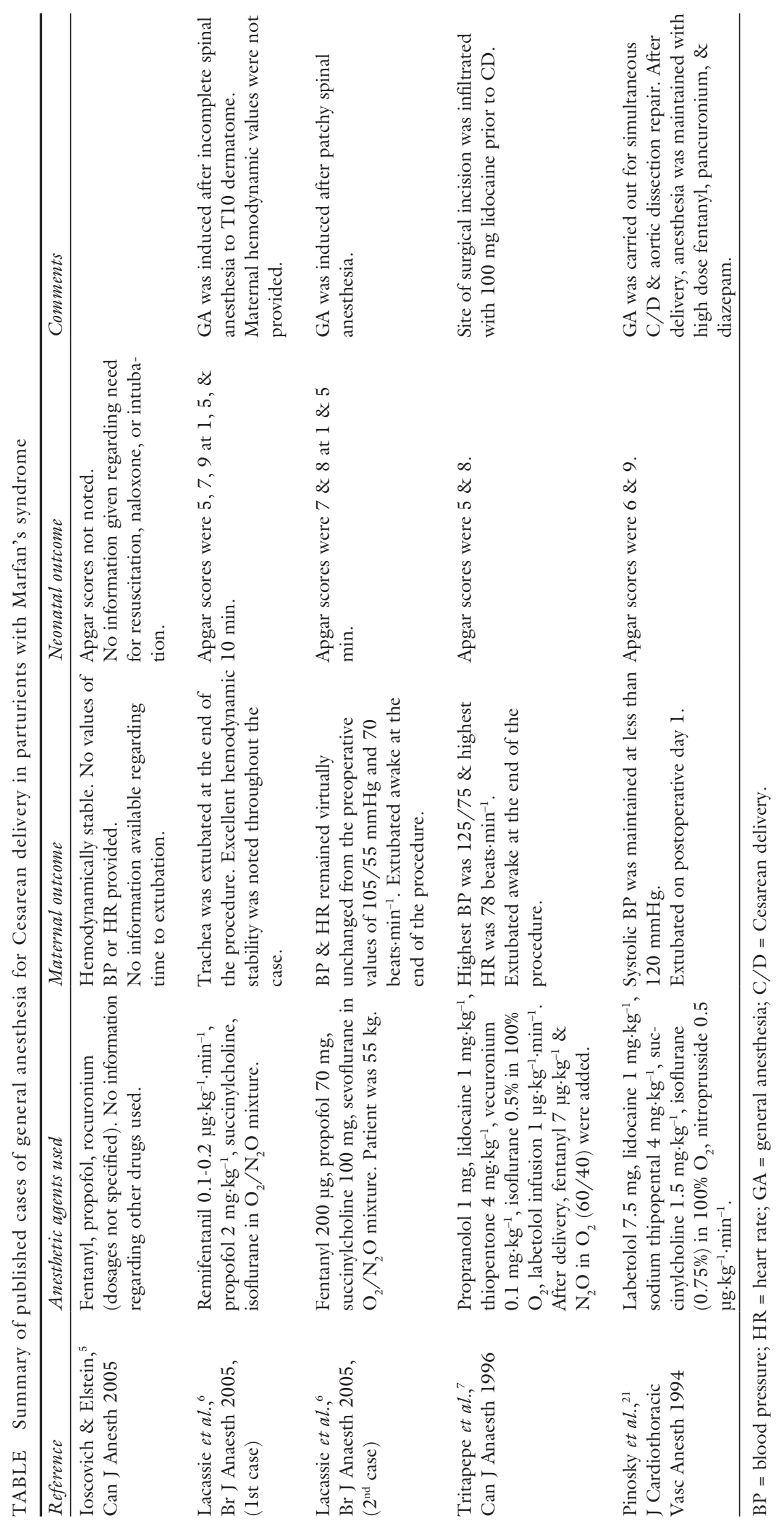




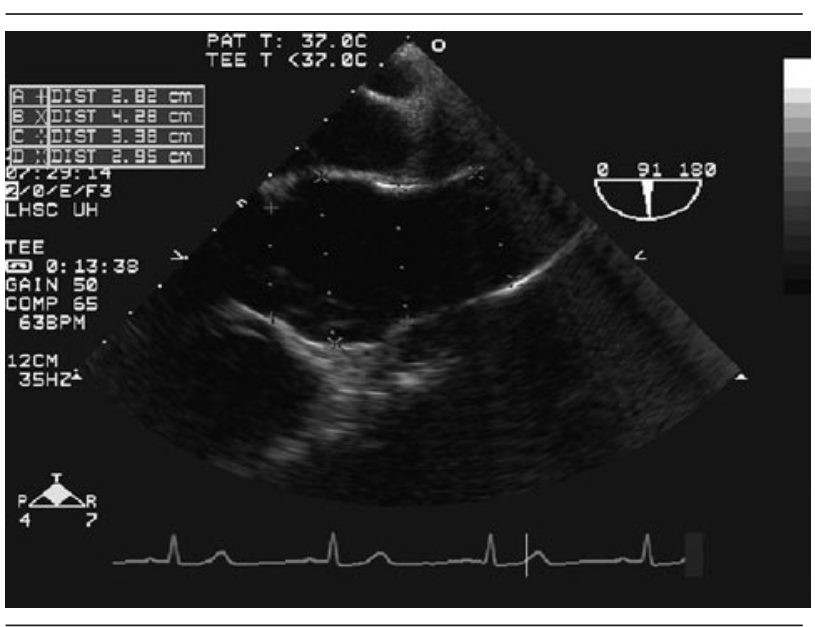

FIGURE Intraoperative transesophageal echocardiogram image, showing dilated aortic valve annulus, and A dilated aortic root sinus of valsalva $($ diameter $=4.28 \mathrm{~cm})$.

our patient, if not prevented with appropriate pharmacology. Failed intubation and aspiration are risks in the obstetric patient. The airway examination of our patient was reassuring, so we felt that a modified rapid sequence induction with cricoid pressure was appropriate, to allow maintenance of hemodynamic stability and rapid control of the airway.

After discussion with the patient and careful assessments of her airway and lumbar spine, we chose to proceed with general anesthesia using remifentanil, a synthetic opioid providing rapid analgesia. It is metabolized by plasma cholinesterase, and its context-sensitive half-time is less than eight minutes. Remifentanil, like other opioids, crosses the placenta, but it is rapidly metabolized and redistributed in both mother and fetus. ${ }^{11}$ Other opioids, such as fentanyl, may cause prolonged neonatal respiratory depression. Numerous case reports, describing use of remifentanil for Cesarean delivery, have shown that remifentanil provides maternal hemodynamic stability with minimal neonatal respiratory depression. ${ }^{12,13}$ Others have described the need for naloxone at birth, ${ }^{14}$ neonatal chest wall rigidity, ${ }^{15}$ and severe fetal bradycardia. ${ }^{16} \mathrm{~A}$ recent study showed that a bolus dose of $1 \mu \mathrm{g} \cdot \mathrm{kg}^{-1}$ of remifentanil, during induction of general anesthesia for Cesarean delivery, blunts maternal cardiovascular effects of intubation, but may cause neonatal depression. ${ }^{17}$ We ensured that a neonatal team was present to resuscitate the baby, if required.

Cesarean delivery under general anesthesia carries a high risk for awareness, which can be associated with hyperdynamic cardiovascular responses. ${ }^{18}$ Studies have shown that use of BIS monitoring to guide general anesthesia, reduces awareness and recovery times. ${ }^{19}$ Remifentanil has been shown to blunt increases in BIS after tracheal intubation. ${ }^{20}$ In our patient, the BIS values (40-57), during the Cesarean delivery, were reassuring.

Transesophageal echocardiography was used intraoperatively, to monitor the aortic root diameter. No significant changes were observed, and no interventions were required. Another risk period for aortic dissection occurs immediately post-partum, because the release of aortocaval compression and autotransfusion of uteroplacental blood increases cardiac output to a maximum. Our patient was monitored in hospital, for seven days prior to discharge. She was also re-educated regarding the symptoms of aortic dissection and instructed to immediately obtain medical help, should they occur.

A literature search (PubMed and Medline, English language, 1966-2007) indicated one other report of a patient with Marfan's syndrome, who, after an incomplete spinal block to T10 dermatome level (Table), received general anesthesia with remifentanil for Cesarean delivery. It is possible that spinal anesthesia contributed to the maternal hemodynamic stability and early extubation noted. Other cases of general anesthesia for Cesarean delivery in Marfan parturients are summarized in the Table.

In summary, we have demonstrated that, with a multidisciplinary approach, adequate preparation, and close monitoring of the patient, Cesarean delivery in a parturient with Marfan's syndrome and aortic dilation can be expedited under general anesthesia with remifentanil. Our patient remained hemodynamically stable, and the infant demonstrated no evidence of prolonged respiratory depression. When neonatal resuscitation support is available, remifentanil is a useful adjuvant for general anesthesia in parturients for whom increases in BP and HR would be detrimental.

\section{Acknowledgements}

The authors are grateful to Drs. Bert Quaghebeur and Ivan Iglesias for their expert help in obtaining, interpreting, and storing the transesophageal echocardiography images.

\section{References}

1 Dean JC. Marfan syndrome: clinical diagnosis and management. Eur J Hum Genet 2007; 15: 724-33.

2 Lalchandani S, Wingfield M. Pregnancy in women with Marfan's syndrome. Eur J Obstet Gynecol Reprod Biol 2003; 110: 125-30.

3 Meijboom LJ, Vos FE, Timmermans J, Boers GH, Zwinderman AH, Mulder BJ. Pregnancy and aortic 
root growth in the Marfan syndrome: a prospective study. Eur Heart J 2005; 26: 914-20.

4 Lind J, Wallaceburg HC. The Marfan syndrome and pregnancy: a retrospective study in a Dutch population. Eur J Obstet Gynecol Reprod Biol 2001; 98: 28-35.

5 Ioscovich A, Elstein D. Images in Anesthesia: Transesophageal echocardiography during Cesarean section in a Marfan's patient with aortic dissection. Can J Anesth 2005; 52: 737-8.

6 Lacassie HJ, Millar S, Leithe LG, et al. Dural ectasia: a likely cause of inadequate spinal anaesthesia in two parturients with Marfan's syndrome. Br J Anaesth 2005; 94: 500-4.

7 Tritapepe L, Voci P, Pinto G, Brauneis S, Menichetti A. Anaesthesia for caesarean section in a Marfan patient with recurrent aortic dissection. Can J Anaesth 1996; 43: 1153-5.

8 Tilak M, Smith J, Rogers D, Fox P, Muntazar M, Peyton $M$. Successful near-term pregnancy outcome after repair of a dissecting thoracic aortic aneurysm at 14 weeks gestation. Can J Anesth 2005; 52: 1071-5.

9 Brar HB. Anaesthetic management of a caesarean section in a patient with Marfan's syndrome and aortic dissection. Anaesth Intensive Care 2001; 29: 67-70.

10 Lipscomb KJ, Smith JC, Clark B, Donnai P, Harris R. Outcome of pregnancy in women with Marfan's syndrome. Br J Obstet Gynaecol 1997; 104: 201-6.

11 Kan RE, Hughes SC, Rosen MA, Kessin C, Preston PG, Lobo ER. Intravenous remifentanil: placental transfer, maternal and neonatal effects. Anesthesiology 1998; 88: 1467-74.

12 Richa F, Yazigi A, Nassar E, Dagher C, Antakly MC. General anesthesia with remifentanil for cesarean section in a patient with HELLP syndrome. Acta Anaesthesiol Scand 2005; 49: 418-20.

13 Orme RM, Grange CS, Ainsworth QP, Grebenik CR. General anaesthesia using remifentanil for caesarean section in parturients with critical aortic stenosis: a series of four cases. Int J Obstet Anesth 2004; 13: 183-7.

14 Imarengiaye C, Littleford J, Davies S, Thapar K, Kingdom J. Goal oriented general anesthesia for cesarean section in a parturient with a large intracranial epidermoid cyst. Can J Anesth 2001; 48: 884-9.

15 Carvalho B, Mirikitani EJ, Lyell D, Evans A, Druzin $M$, Riley ET. Neonatal chest wall rigidity following the use of remifentanil for cesarean delivery in a patient with autoimmune hepatitis and thrombocytopenia. Int J Obstet Anesth 2004; 13: 53-6.

16 Ong BY, Baron K, Steam EL, Baron C, Paetkau D, Segstro $R$. Severe fetal bradycardia in a pregnant surgical patient despite normal oxygenation and blood pressure. Can J Anesth 2003; 50: 922-5.
17 Ngan Kee WD, Khaw KS, Ma KC, Wong AS, Lee BB, $\mathrm{Ng}$ FF. Maternal and neonatal effects of remifentanil at induction of general anesthesia for cesarean delivery: a randomized, double-blind, controlled trial. Anesthesiology 2006; 104: 14-20.

18 Yeo SN, Lo WK. Bispectral index in assessment of adequacy of general anaesthesia for lower segment caesarean section. Anaesth Intensive Care 2002; 30: 36-40.

19 Punjasawadwong $\Upsilon$, Boonjeungmonkol $N$, Phongchiewboon A. Bispectal index for improving anaesthetic delivery and postoperative recovery. Cochrane Database Syst Rev 2007; (4): CD003843.

20 Guignard B, Menigaux C, Dupont X, Fletcher D, Chauvin $M$. The effect of remifentanil on the index image change and hemodynamic responses after orotracheal intubation. Anesth Analg 2000; 90: 161-7.

21 Pinosky ML, Hopkins RA, Pinckert TL, Suyderhoud JP.

Anesthesia for simultaneous cerarean section and acute aortic dissection repair in a patient with Marfan's syndrome. J Cardiothorac Vasc Anesth 1994; 8: 45l-4. 